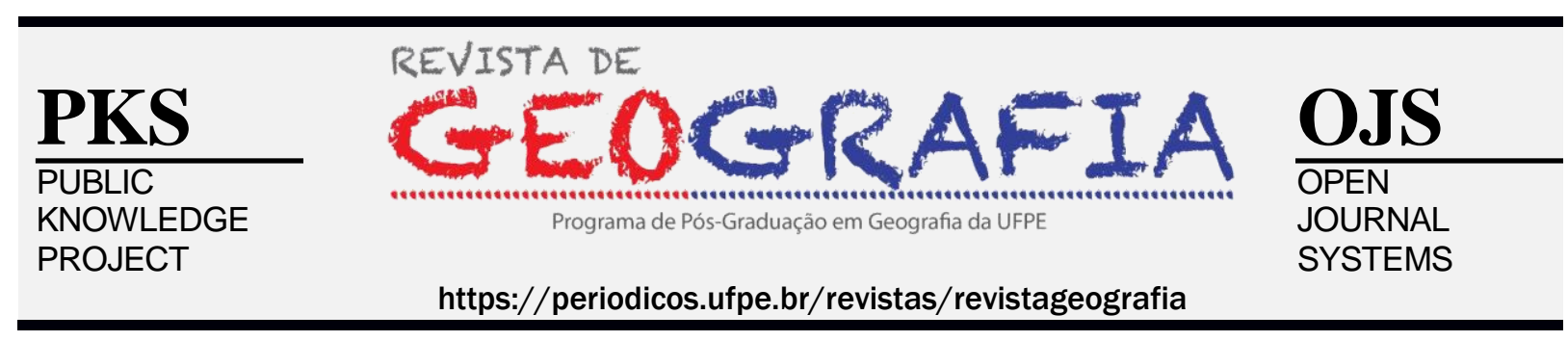

\title{
MINERAÇÃO EM GRANDE ESCALA, DISPUTAS PELO SUBSOLO E O ESPAÇO AGRÁRIO FRATURADO EM GOIÁS, BRASIL ${ }^{1}$
}

\author{
Ricardo Junior de Assis Fernandes Gonçalves ${ }^{1}$ \\ ${ }^{1}$ Universidade Estadual de Goiás (UEG). Pós-Doutorando no Programa de Pós-Graduação em Geografia da \\ Universidade Federal de Juiz de Fora (UFJF). Grupo Política, Economia, Mineração, Ambiente e Sociedade \\ (PoEMAS).E-mail:ricardo.goncalves@ueg.br
}

Artigo recebido em 08/03/19 e aceito em 22/06/19

\begin{abstract}
RESUMO
Neste artigo, discute-se a mineração em grande escala, a integração de Goiás nas redes globais extrativas e as implicações territoriais nas distintas formas de organização da vida e do trabalho no espaço agrário goiano. Além disso, debate-se elementos que tocam a relação entre mineração e espaço agrário, propiciando uma reflexão geográfica crítica a respeito desse setor extrativo. A metodologia utilizada na pesquisa contou com técnicas de levantamento de dados e informações qualitativas e quantitativas ilustradas em tabelas e mapas. Além da introdução, a primeira parte deste artigo demonstra o papel da mineração no processo de integração de Goiás nas redes globais extrativas no contexto de boom das commodities. Na segunda parte, evidencia-se que a expansão do setor extrativo mineral impôs novas escalas de apropriação e controle do subsolo, sobrepondo interesses minerários em espaços tradicionalmente ocupados por quilombolas, camponeses assentados e posseiros. Por fim, as considerações finais sublinham debates que apontam à necessidade de se transformar radicalmente o modelo de mineração em operação no Brasil e em Goiás.
\end{abstract}

Palavras-chave: Goiás; Mineração; Subsolo; Espaço agrário; Conflitos.

\section{LARGE-SCALE MINING, DISPUTES FOR SUBSOL AND AGRARIAN SPACE FRATURATED IN GOIÁS, BRASIL}

\begin{abstract}
In this article it is discussed large-scale mining, the integration of Goiás into extractive global networks and territorial implications in the different forms of organization of life and work in the agrarian space of Goiás. In addition, it is argued elements that approach the relationship between mining and agrarian space providing a critical geographic reflection on this extractive sector. The methodology applied in the research relied on data collection techniques and qualitative and quantitative information, illustrated in tables and maps. In addition to the introduction, the first part of this article demonstrates the function of mining in the process of integrating Goiás into global extractive networks in the context of a commodity boom. In the second part, it is evident that the expansion of the mineral extractive sector established new scales of appropriation and control of the subsoil, especially mining interests in places traditionally occupied by quilombolas, settled peasants and squatters.
\end{abstract}

\footnotetext{
${ }^{1}$ Parte dos dados apresentados na pesquisa estão na tese do autor, defendida em agosto de 2016. Para este artigo atualizamos informações e incrementamos novos elementos da discussão teórica e metodológica.

O pesquisador agradece a CAPES e a FAPEG pela bolsa de Pós-Doutorado aprovada no âmbito da Chamada Pública n.9/2018.
} 
Finally, the final considerations underline debates that point to the need to radically transform the mining standard in action in Brasil and in Goiás.

Keywords: Goiás; Mining; Subsoil; Agrarian place; Conflicts.

\section{INTRODUÇÃO}

Cada pétala de ouro foi arrancada com sangue.

Cada metal tem um soldado. (Pablo Neruda, 1980)

Por ouro, ferro, níquel, nióbio, cobre e diamantes, além de água, petróleo e gás natural, localizados e explotados em pontos estratégicos de regiões, países e continentes, acordos geopolíticos, intervenções militares, guerrilhas e crimes foram e são cometidos, povoando os territórios de medo e insegurança. No Brasil, as reservas de minérios são cartografadas por interesses do Estado e de capitalistas nacionais e estrageiros, resultando na apropriação e controle desigual dos bens comuns naturais. Ademais, inspirado nos versos do poeta Pablo Neruda, pode-se dizer que há na matéria bruta de cada tipo de minério extraído do subsolo o suor e o sangue de trabalhadores e de comunidades expropriadas dos seus territórios.

A territorialização de megaempreendimentos de mineração no Brasil baseia-se na intervenção ambiental em grande escala e no controle corporativo dos territórios. Implica processos econômicos, ambientais, políticos e sociais que dependem da transformação dos bens comuns naturais em commodities que movimentam o mercado mundial de minérios controlado por grandes corporações. Além disso, o modelo de mineração no país, responsável por desastres socioambientais como em Mariana/MG (novembro de 2015) e Brumadinho/MG (janeiro de 2019), é um modelo de conflitos e riscos estruturais para trabalhadores e comunidades.

Sendo assim, neste artigo, discute-se a integração de Goiás nas redes globais extrativas e as implicações da expansão da mineração em grande escala nas distintas formas de organização da vida e do trabalho no espaço agrário. Comunidades Camponesas, territórios quilombolas, assentamentos rurais e terras de camponeses posseiros são pressionadas e fraturadas pela mineração e os interesses do setor por recursos minerais ainda inexplorados. Logo, constata-se que além de terra e água, o subsolo está em disputa no espaço agrário brasileiro.

A metodologia utilizada na pesquisa contou com técnicas de levantamento de dados e informações qualitativas e quantitativas, como pesquisa de campo, entrevistas, dados de 
fontes como a Agência Nacional de Mineração (ANM), Instituto Nacional de Colonização e Reforma Agrária (INCRA) e Fundação Palmares, organizados em tabelas e representados em mapas.

Em suma, ao longo do artigo debate-se elementos que tocam a relação entre mineração e questão agrária, propiciando uma reflexão crítica a respeito desse setor extrativo e os impactos na organização dos territórios em Goiás. Além da introdução, a primeira parte do artigo demonstra o papel da mineração no processo de integração de Goiás nas redes globais extrativas no contexto de boom das commodities. Na segunda parte, evidencia-se que a expansão do setor extrativo mineral implicou em novas escalas de apropriação e controle do subsolo, sobrepondo interesses minerários em espaços tradicionalmente ocupados por quilombolas, camponeses assentados e posseiros. Por fim, as considerações finais sublinham debates que retomam informações do texto e apontam para a necessidade de se transformar radicalmente o modelo de mineração em operação no Brasil e em Goiás.

\section{A INTEGRAÇÃO DE GOIÁS NAS REDES GLOBAIS EXTRATIVAS}

O início do século XXI representou, para o setor extrativo mineral, um cenário de alta lucratividade diante do aumento dos preços das commodities minerais no mercado internacional, a exemplo do minério de ferro (62\% de teor), cujo preço da tonelada subiu de US\$ 12,60 a tonelada em maio de 2002 para US\$ 187,10 em janeiro de 2011 (BANCO MUNDIAL, 2016; WANDERLEY, 2017).

A mesma tendência impactou os preços e as ofertas do níquel, estanho, carvão mineral, ouro e alumínio. No entanto, o minério de ferro foi o caso mais emblemático: de 500 milhões de toneladas em 2001, a importação global desse minério saltou para 1.394 milhões de toneladas em 2014, um crescimento de $178 \%$. Consequentemente, isso ocorreu em sintonia com as mudanças de comportamento do mercado financeiro (MILANEZ, 2017) e as demandas dos países emergentes, em especial a China, que de $18 \%$ em 2001, passou a ser responsável por 67\% das importações globais do minério de ferro em 2014 (ITC, 2017; WANDERLEY, 2017).

Denominado de superciclo ou boom das comodities minerais (2003-2011), esse contexto reconfigurou as ações das empresas e regiões mineradas na América Latina e particularmente no Brasil. Com efeito, as intervenções em grande escala nos territórios diante 
abertura e ampliação de minas a céu aberto, barragens para disposição de rejeitos, duplicação de ferrovias, construção de minerodutos e terminais portuários contribuíram para acelerar os ritmos extrativos e as exportações de minérios explotados no subsolo brasileiro.

Logo, as operações minerais subiram da ordem de $\mathrm{R} \$ 17,6$ bilhões em 2004 para $\mathrm{R} \$$ 85,6 bilhões em 2011 (ANM, 2019). Por sua vez, a arrecadação da Compensação Financeira pela Exploração de Recursos Minerais (CFEM) - os royalties da mineração - subiu, no mesmo período, em valores nominais (assim como todos os demais valores apresentados no texto), de $\mathrm{R}$ \$ 323 milhões para R \$ 1,5 bilhão. Finalmente, destaca-se o aumento da participação dos minérios na pauta exportadora do país, que representava 6,8\% em 2000 e subiu para 17,6\% em 2011 (GONÇALVES, 2018; ANM, 2019).

A expansão das fronteiras do capital extrativo no Brasil implicou em novas escalas de intervenção nos territórios e processos de comoditização das "dádivas gratuitas da natureza” (HARVEY, 2018). À vista disso, destaca-se a participação e a integração do BiomaTerritório Cerrado e de Goiás nas redes globais extrativas. Em 2018, o valor das operações da mineração somou $\mathrm{R} \$ 4,9$ bilhões, enquanto a arrecadação de CFEM foi de 98,7 milhões. Um crescimento significativo quando comparado a 2004, ano em que as operações minerais somaram $\mathrm{R} \$ 1,1$ bilhão, e a arrecadação de CFEM alcançou $\mathrm{R} \$ 14,3$ milhões distribuídos entre os municípios goianos minerados (ANM, 2005; 2019). Esses dados posicionam Goiás na terceira posição entre os principais estados brasileiros minerados, após Minas Gerais e Pará.

Por conseguinte, ao se aproximar as cifras da extração mineral em grande escala em Goiás e a conjuntura global de boom das commodities minerais, percebe-se que o recorte temporal delimitado entre 2004 e 2012 é fundamental para a análise geográfica do comportamento desse setor extrativo no estado. O peso da mineração na economia goiana e nos municípios minerados foi incrementado com o aumento do volume de minérios extraídos e das cifras de comercialização. O valor total da comercialização dos minérios explotados saltou de R \$ 2,4 bilhões em 2004 para R \$ 6,7 bilhões em 2012 (ANM, 2014).

No período analisado (2004-2012), entre os minerais explotados pelos grandes projetos em Goiás, o ouro, níquel, cobre e nióbio são os exemplos que ilustram de maneira significativa tanto a expansão do volume extraído quanto as cifras dos valores das comercializações. (Tabela 1). 


\begin{tabular}{c|c|c|c|c}
\multirow{2}{*}{ Minérios /Período } & \multicolumn{2}{|c|}{$\mathbf{2 0 0 4}$} & \multicolumn{2}{c}{$\mathbf{2 0 1 2}$} \\
\cline { 2 - 5 } & $\begin{array}{c}\text { Produção } \\
\text { (t e Kg/Ouro) }\end{array}$ & $\begin{array}{c}\text { Comercialização } \\
(\mathbf{R} \$)\end{array}$ & $\begin{array}{c}\text { Produção } \\
\text { (t e Kg/Ouro) }\end{array}$ & $\begin{array}{c}\text { Comercialização } \\
\text { (R\$) }\end{array}$ \\
\hline Ouro & 8.552 & $354.872 .236,97$ & $14.956,39$ & $1.159 .939 .524,77$ \\
\hline Níquel & 26.390 & $1.078 .197 .482,00$ & $65.177,57$ & $2.274 .647 .347,95$ \\
\hline Cobre & 1.432 & $11.605 .000,00$ & $75.055,02$ & $1.211 .883 .385,93$ \\
\hline Nióbio & 5.373 & $129.264 .254,00$ & $13.037,38$ & $334.918 .567,01$
\end{tabular}

Tabela 1 - Produção e valores da comercialização de ouro, níquel, cobre e nióbio - Goiás, 2004 e 2012.

Fonte: ANM (2005; 2014).

Org.: o autor (2019).

O crescimento da produção e dos valores da comercialização dos minérios ilustrados na tabela 1 contribuem também para a análise da integração de Goiás nas redes globais extrativas, na medida em que o estado se tornou um importante exportador. Assim, o nióbio em Catalão e Ouvidor, o cobre em Alto Horizonte, o níquel em Barro Alto e Niquelândia, o ouro em Crixás, Faina, Guarinos e Pilar de Goiás, além o amianto em Minaçu, foram e continuam sendo exportados para diferentes países e continentes. (Mapa 1).

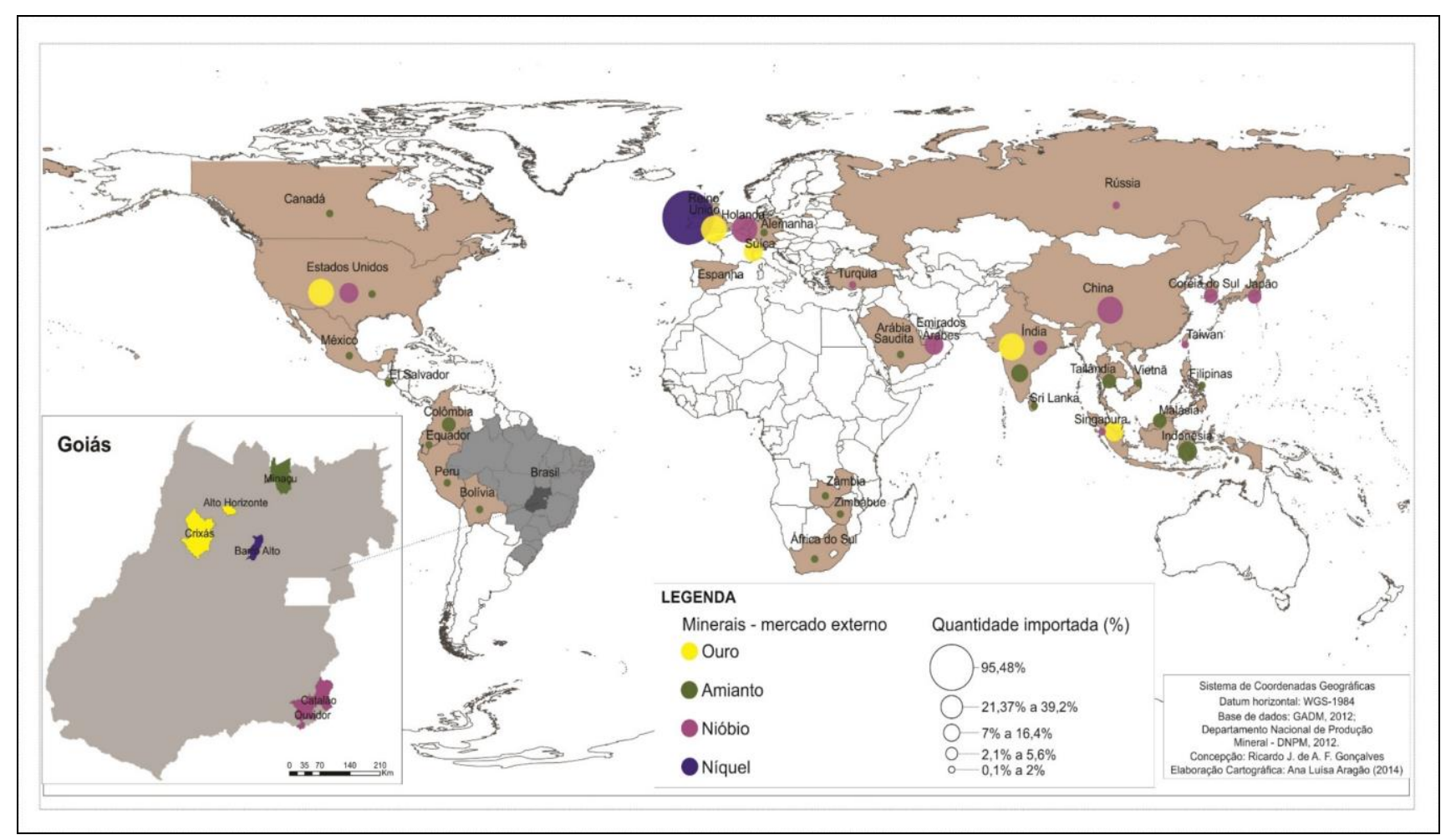

Mapa 1 - Minerais extraídos em Goiás e destinados ao mercado mundial.

Concepção: o autor (2014).

Elaboração: Aragão (2014)

O destino dos minerais extraídos do subsolo do Bioma-Território Cerrado em Goiás representa uma cartografia das exportações distribuída entre diferentes países e continentes, 
conforme os tipos de minérios e sua relação com as demandas e o desenvolvimento das forças produtivas de cada importador. Isso quer dizer que a espacialidade da extração dos minérios como o ouro, nióbio, níquel e amianto, possui vínculos diferenciados com a espacialidade do consumo de tais minerais. Tal fato fortalece a posição subordinada e desigual entre os países e regiões produtoras, como Goiás e o Brasil, aos países consumidores como a China, Estados Unidos, Reino Unido, Alemanha etc., na Divisão Internacional do Trabalho.

Sendo assim, o mapa 1 demonstra que o ouro extraído em Goiás em 2012 foi exportado para a Holanda, Estados Unidos, Suíça e Índia. O nióbio, por sua vez, exemplifica a cartografia desigual entre extração e consumo, com a produção importada por países da Europa, América do Norte e da Ásia, que demandam esse metal para aplicações em setores de alta tecnologia, como a indústria armamentista e aeroespacial. Da mesma forma, o níquel, comprado pelo Reino Unido.

Outro destaque dessas observações é o amianto crisotila. No entanto, diferente do ouro, níquel e nióbio, requerido e aplicados em produtos de alta tecnologia dos países que dominam as revoluções tecnológicas, o amianto foi importado especialmente por economias emergentes do hemisfério sul, localizadas na África, Ásia, Oceania e América do Sul. Isso se deve tanto pelo nível das forças produtivas de cada região ou país importador quanto à proibição no uso do amianto, sobretudo nos países da União Europeia, resultando numa reconfiguração geopolítica do mercado internacional para este minério extraído em Minaçu/GO².

Observa-se que a mineração está integrada às redes globais de comércio de minérios e continua desempenhando um papel central entre os principais produtos exportados por Goiás. Em 2017, o complexo de minérios representou o segundo principal produto das exportações goianas, com um valor de U\$ FOB 1,4 bilhões - o primeiro foi o complexo de soja, com um valor de U\$ FOB 2,6 bilhões, e terceiro o complexo de carnes, com U\$ FOB 1,2 bilhões (IMB, 2017).

Diante disso, sublinha-se que os territórios com jazidas ricas em minérios são sistematicamente usurpados pela economia primário-exportadora. Assim, a apropriação do subsolo torna-se necessária para manter o controle privado das " [...] dádivas gratuitas da

\footnotetext{
${ }^{2}$ Destaca-se que em 2017 o Supremo Tribunal Federal (STF), "por maioria de votos, reafirmou a declaração de inconstitucionalidade do artigo $2^{\circ}$ da Lei federal 9.055/1995 que permitia a extração, industrialização, comercialização e a distribuição do uso do amianto na variedade crisotila no país" (STF, 2017, p.1). A decisão teve implicações diretas na economia de Minaçu, município com a única mina a céu aberto de amianto crisotila em operação no país.
} 
natureza, uma vez que o capital busca cada vez mais cercá-las e privatizá-las para extrair renda" (HARVEY, 2018, p. 119). Por consequência, comunidades camponesas, terras devolutas ocupadas por posseiros, terras indígenas, territórios quilombolas e assentados de reforma agrária passam a ser pressionados e fraturados pelos interesses da mineração, conforme constatado em Goiás.

\section{SUBSOLO EM DISPUTA E O ESPAÇO AGRÁRIO FRATURADO}

No Brasil, conforme o Art. 20 da Constituição Federal (BRASIL, 1988), “os recursos minerais, inclusive os do subsolo" são bens da União. Além disso, constituem propriedade distinta da do solo (BRASIL, 1988, Art.176). Com efeito, as atividades de pesquisa (exploração) ou explotação (lavra) mineral dependem de autorizações da ANM (antigo DNPM, e responsável pela outorga de pesquisa) e Ministério de Minas e Energia (autorização de lavra). Ademais, tanto pessoas físicas quanto jurídicas constituídas em território nacional estão autorizadas a requerer direitos de pesquisa e lavra ${ }^{3}$.

Sendo assim, ao mesmo tempo em que cresceram os grandes projetos de extrativismo mineral no Brasil no contexto de boom das commodities minerais, o subsolo do país passou a ser mapeado e controlado pelos interesses do setor mineral em busca de potenciais jazidas. No período entre 2003 e abril de 2012 foram encaminhados aproximadamente 182.463 requerimentos de pesquisa à ANM, sendo 136.718 autorizadas, 74,93\% do total. Ainda, houve 2.946 concessões de lavra e 1.299 permissões de lavra garimpeira executadas pelo MME no mesmo período (SANTOS, 2012; ANM, 2014).

Com ênfase em Goiás, um dos principais estados minerados do país, e considerando a extensão de suas fronteiras e a presença dominante do Cerrado em seu território, destaca-se a importância estratégica do seu subsolo. Assim, os aspectos geológicos não estão dissociados dos mecanismos que mercantilizam e internacionalizam o Cerrado goiano. Isso possui implicações sobre a compreensão geográfica do espaço agrário e seus conflitos, pois além de terra e água, o subsolo também influencia nas disputas territoriais.

Dessa maneira, a análise dos eventos minerais (requerimentos e títulos minerários) publicados pela ANM, no período entre 2000 e 2011 em Goiás, revela o comportamento do

\footnotetext{
${ }^{3}$ Conforme o atual Código de Mineral, para ter o direito de lavra é preciso passar por um conjunto de etapas, (detalhadas no Guia do Minerador - ANM. Guia do Minerador. 2015. Disponível em: <http://www.dnpmpe.gov.br/Legisla/Guia/Guia_2.htm>. Acesso em: 23 de jun./2015), sendo, Requerimento de pesquisa; Autorização de pesquisa; Relatório de trabalho de pesquisa; Requerimento de lavra; Concessão de lavra.
} 
setor extrativo mineral e o grau de interesse que envolvem a apropriação do subsolo no período considerado (Tabela 2). Assim sendo, expor esses interesses contribui para reafirmar o que se defende na pesquisa: as disputas pelo subsolo.

\begin{tabular}{c|c|c|c|c} 
Eventos Minerários & $\mathbf{2 0 0 0}$ & $\mathbf{2 0 0 4}$ & $\mathbf{2 0 0 8}$ & $\mathbf{2 0 1 1}$ \\
\hline $\begin{array}{c}\text { Requerimento de } \\
\text { pesquisa }\end{array}$ & 818 & 1.255 & 2.675 & 2.454 \\
\hline $\begin{array}{c}\text { Autorização de } \\
\text { pesquisa }\end{array}$ & 1.020 & 885 & 2.305 & 1.890 \\
\hline $\begin{array}{c}\text { Requerimento de } \\
\text { lavra }\end{array}$ & 36 & 115 & 99 & 90 \\
\hline Concessão de lavra & 11 & 99 & 23 & 14
\end{tabular}

Tabela 2 - Evolução dos requerimentos e dos títulos minérios em Goiás (incluindo o Distrito Federal) - 2000, 2004, 2008 e 2011.

Fonte: DNPM (204, 2008, 2012)

Org.: o autor (2019).

A tabela 2 revela que no período considerado os interesses pelo subsolo foram fortalecidos diante do aumento de eventos como os requerimentos e autorizações de pesquisa. Da mesma forma, os requerimentos e autorizações de lavra aumentaram significativamente, com um pico no ano de 2004. Isto posto, o mapa 2, abaixo, incrementa essas informações e contribui para a compreensão geográfica da legenda espacial dos requerimentos e títulos minerários. Isto é, a maneira como estão distribuídos nas diferentes regiões de Goiás. Ainda, a cartografia dos eventos minerários no território goiano está distribuída conforme a geologia do norte, sul, leste e oeste goiano (CPRM, 2000).

No entanto, no caso específico dos requerimentos e títulos minérios, distribuídos no mapa geográfico de Goiás, a relação entre o controle do subsolo e a exploração e explotação mineral das áreas nem sempre coincidem. Isso significa que a pessoa física ou jurídica detém o título de uma área e não desenvolve nenhuma atividade de pesquisa ou extração de bens minerais, muitas vezes servindo, assim, como manobra especulativa ${ }^{4}$.

\footnotetext{
${ }^{4}$ Mudanças no modelo vigente das concessões de pesquisa e direito de lavra têm motivado debates no âmbito de um novo marco regulatório da mineração. Sobre o assunto, ver Gonçalves et.al (2018).
} 


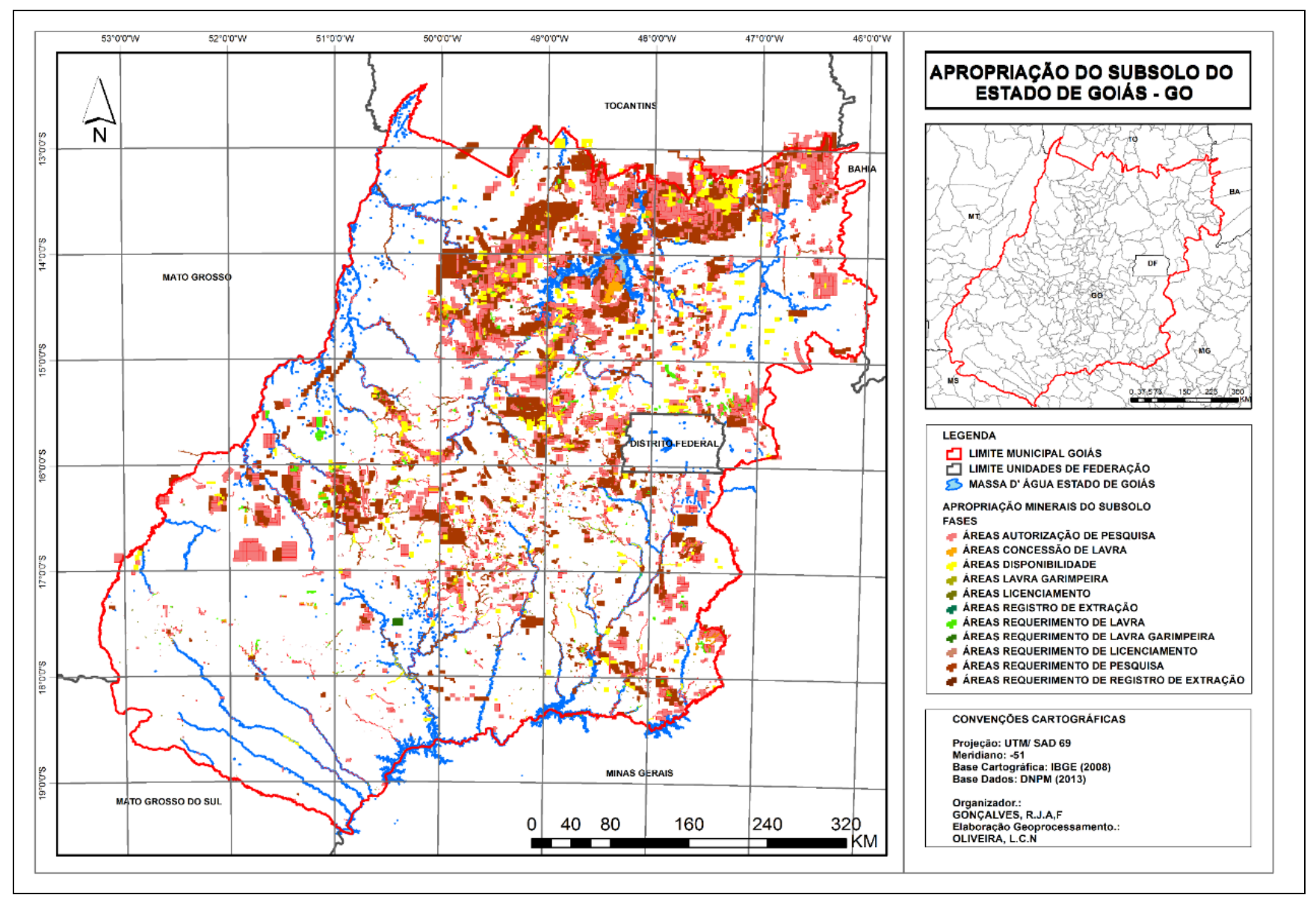

Mapa 2 - O subsolo "loteado" em Goiás.

Concepção: o autor (2014).

Elaboração: Oliveira (2014).

O mapa 2 ilustra que os interesses pelo subsolo palmilham as distintas regiões de Goiás e vasculham os potenciais naturais de cada lugar. As especialidades produtivas, a relação entre a produção social e os recursos territoriais de cada lugar, como a terra, a água e os minérios. Nesse sentido, um olhar atento no mapa 2 expõe a concentração do processo de apropriação e controle do subsolo no norte e nordeste do Estado, regiões onde já se concentram os megaempreendimentos de mineração a céu aberto de ouro, níquel, cobre e amianto. Isso demonstra seu papel estratégico do ponto de vista geológico e econômico frente aos novos grandes projetos de extrativismo mineral, como o da Mineração Serra Verde (Grupo Mining Ventures Brasil) em Minuçu (exploração de terras raras) e Amarillo Mineração do Brasil (Amarillo Gold Corp.) em Mara Rosa (exploração de ouro).

Assim, percebe-se que o Norte e Nordeste de Goiás são territórios povoados por interesses minerários que fomentam a atuação do capital, equanto as populações locais 
experimentam os efeitos da produção desigual e combinada. São territórios fraturados e continuamente mapeados para atividades de mineração, turismo e hidroeletricidade. Consequentemente, lastreados por histórias de conflitos, grilagem de terras, perseguições e ameaças a militantes, assassinatos de camponeses, quilombolas e indígenas.

Ainda que as estratégias de exploração impõem a "pilhagem territorial" (PERPETUA, 2016) dos lugares, homens e mulheres resistiram e resistem. Essas constatações podem ser exemplificadas pela revolta e resistência organizadas pelos posseiros de Formoso e Trombas, e liderada por José Porfírio de Sousa (Zé Porfírio), na década de 1950 e prolongada até 1964, quando ocorreu o golpe militar e lideranças camponesas das regiões Norte Goiano e Nordeste Goiano foram perseguidas com violência. A Revolta Camponesa de Formoso e Trombas constituiu-se como um movimento que não só denunciou a opressão exercida pelos grileiros em Goiás, mas, o histórico da luta de classes no campo brasileiro.

Além disso, destaca-se também que as regiões Norte Goiano e Nordeste Goiano são tradicionalmente ocupadas por quilombolas, com destaque para o Território Kalunga, com uma área de 253.000 hectares e 56 comunidades entre os municípios de Monte Alegre de Goiás, Cavalcante e Teresina de Goiás (Mapa 3). Portanto, que apresenta conflitos potenciais diante dos interesses minerários que orbitam esses territórios, as comunidades quilombolas. 


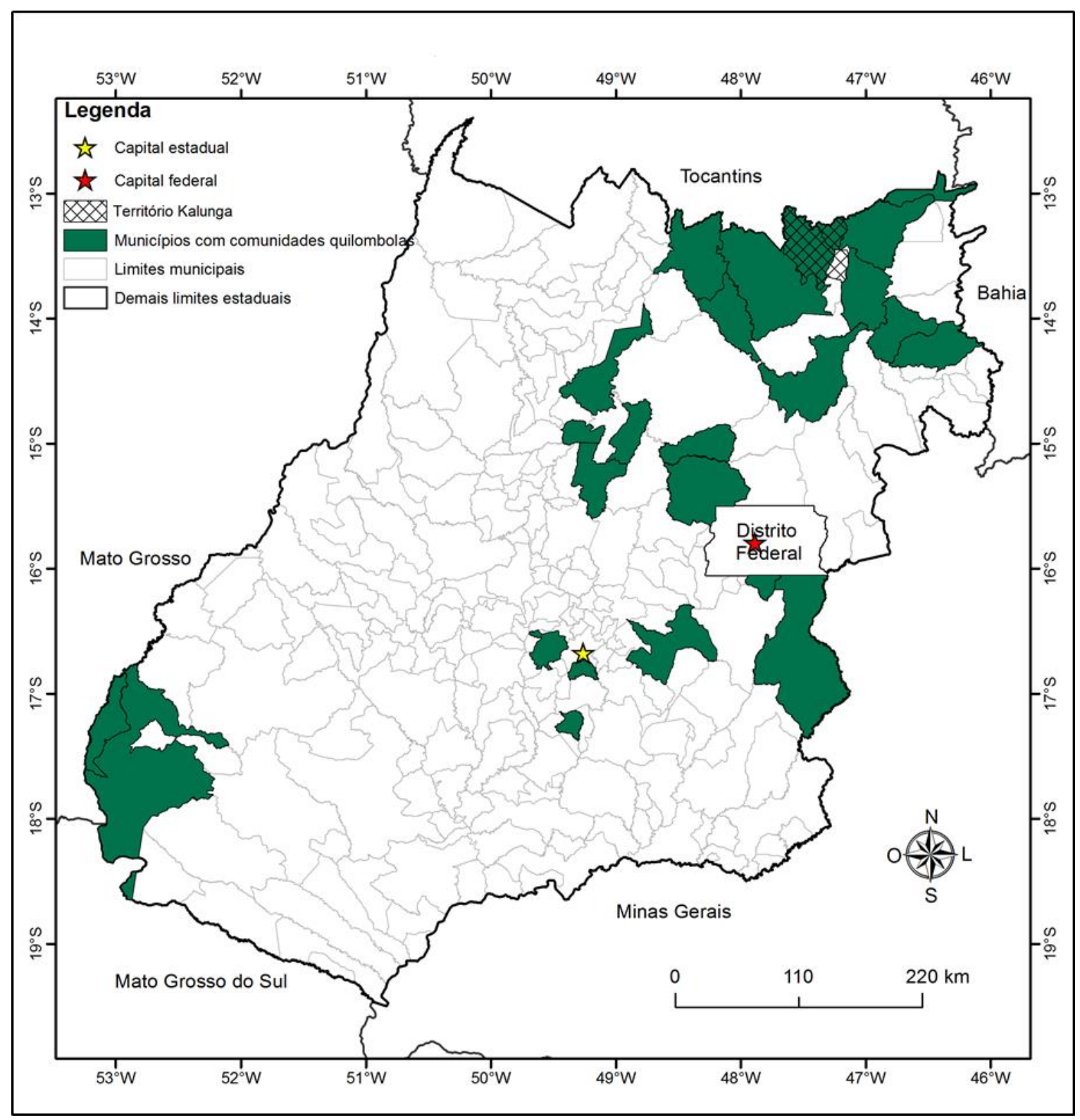

Mapa 3 - Municípios com territórios quilombolas em Goiás. Concepção e Elaboração: Nascimento (2016).

A observação comparativa entre o mapa 2 e o mapa 3 revelam que as áreas mais destacadas pelos interesses minerários comparecem nos municípios com territórios quilombolas especialmente no Nordeste Goiano. Um exemplo axiomático dessas constatações revela-se diante da quantidade de concessões de títulos minerários e área ocupada por esses interesses apenas no Território Kalunga: são 116 títulos minerários que ocupam uma área de 192,7 mil hectares (ANM, 2019). Destarte, são territórios urdidos por relações de ancestralidade, símbolos e identidades que passam a ser mapeados e cindidos pelas riquezas minerais do subsolo em suas terras, fundamentais para as estratégias de expansão e 
acumulação de capital. E, como vaticina Galeano (2013, p. 86): “[...] ocorre que quanto mais ricas são estes territórios, mais grave é a ameaça que pende sobre as vidas dos sujeitos que os habitam; a generosidade da natureza os condena à espoliação e ao crime".

Outrossim, camponeses posseiros e famílias de trabalhadores assentados de reforma agrária, que vivem e trabalham na terra são expostos às estratégias de cercamento pelos interesses minerários. São lugares da vida e da existência coletiva guardiões de potenciais riquezas minerais que agudizam as ações apropriação e controle do subsolo. Logo, resultam em realidades com latentes conflitos com esses sujeitos (superficiários), tanto na etapa da pesquisa (autorizada pelo ANM) quanto da lavra (concessão do MME). Isso compõe um ambiente disputas quanto ao acesso a propriedade e uso da terra e a mineração. Ou seja, da relação entre propriedade do solo e dos recursos minerais do subsolo (BRASIL, 1988, Art. 176).

Em Goiás, vivem centenas de famílias de camponeses posseiros, especialmente nas regiões Norte e Nordeste do estado. A apropriação do subsolo por meio das concessões autorizadas pelo Governo Federal problematiza a situação das famílias que vivem em terras devolutas. A ausência do título da terra fragiliza esses sujeitos diante da territorialização e expansão dos empreendimentos de pesquisa ou lavra mineral, assim como para construção de obras de engenharia logística ou produção de energia, como rodovias, ferrovias e hidrelétricas. Sendo assim, a situação de milhares de posseitos no território goiano, exemplifica as análises e demonstra que a maior parte das terras devolutas ocupadas no estado estão localizadas em municípios onde os interesses minérios são predominantes. (Mapa 4). 


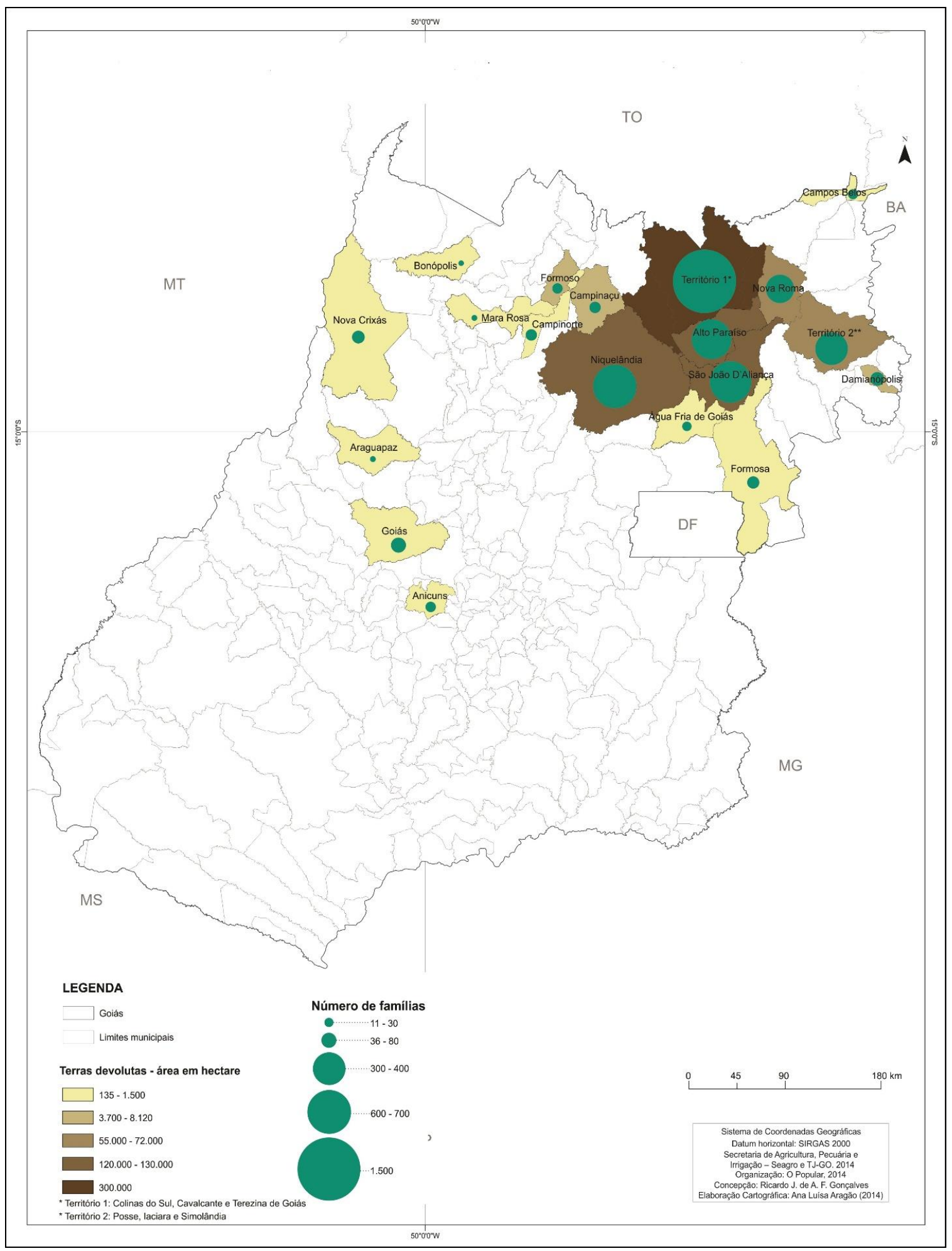

Mapa 4 - Goiás: terras devolutas e número de posseiros, 2014.

Concepção: o autor (2015).

Elaboração: Aragão (2015).

Conforme dados tabulados pelo jornal O Popular (2014, p. 7) são 820 mil hectares em ocupadas por 4,6 mil famílias de camponeses posseiros em Goiás. Essa situação conta ainda 
com 400 processos administrativos e 10 ações judiciais, propostas ainda entre 1979 e a década de $1980^{5}$. São camponeses e camponesas sem a escritura da terra, portanto, sem segurança jurídica diante dos interesses capitalistas ou grileiros, facilitando o processo de expropriação para a instalação de grandes projetos privados como mineração e energia. Em alguns casos como Niquelândia, onde já existem grandes projetos de extrativismo mineral, a sobreposição de interesses entre áreas de títulos minerários e camponesas que ainda vivem no território, pode fomentar conflitos, considerando que são 700 famílias de posseiros ocupando uma área de 120 mil hectares no município.

Além da situação dos posseiros, dezenas de assentamentos e milhares de hectares de lotes das famílias assentadas para fins de reforma agrária representam conflitos de sobreposição entre interesses minerários pelo subsolo e o trabalho na terra. Há em Goiás aproximadamente $7.065 \mathrm{Km}^{2}$ de terra regularizada pelo Instituo Nacional de Colonização e Reforma Agrária (INCRA) para 300 assentamentos rurais distribuídos em 78 municípios, sendo $73 \%$ deles concentrados na regiões Norte, Oeste e Noroeste Goiano ${ }^{6}$. (INCRA, 2015; ESPÍNDOLA ROSA et.al, 2015). Por conseguinte, representam uma espacialidade geográfica que coincide com as áreas de maior interesse minerário no estado. Há 1.093 títulos minerários em 170 dos assentamentos goianos. (Mapa 5).

\footnotetext{
${ }^{5}$ Entre a década de 1950 e 1980 houve um boom de títulos expedidos no contexto de diversos governos estaduais: Coimbra Bueno (1949-1953), 580 títulos expedidos; Juca Ludovico (1954-1958), 1.737 títulos; Mauro Borges (1969-1964), 4.322; Otávio Lage (1966-1971), 5.907; Leonino Caiado (1971-1975), 1.652; Irapuan Costa Júnior (1975-1979), 1.530; Ary Ribeiro Valadão (1979-1983), 5.993; Iris Rezende (1983-1987), 1.540; Henrique Santillo (1987-1990), 2.025. (ALMEIDA, 2014).

Conforme Almeida (2014), a posse ilegal da terra em Goiás, com a presença das famílias nas terras devolutas e morosidade no processo de regularização fundiária, se agravou em 1991, depois da extinção do Instituto de Desenvolvimento Agrário de Goiás (IDAGO), que desempenhava a função de regularizar as terras. Almeida explica ainda que com o fim do IDAGO, a Agência Rural assumiu a tarefa e, em 2002, entregou 700 escrituras, e desde então, não houve regularização de terras devolutas.

${ }^{6}$ Os dados referem-se às regiões de atuação da Superintendência Regional do Incra em Goiás (SR-04), com exceção das regiões Nordeste e do Entorno do Distrito Federal, que estão sob outra jurisdição da Superintendência do Incra, a do Distrito Federal e Entorno (SR-28).
} 


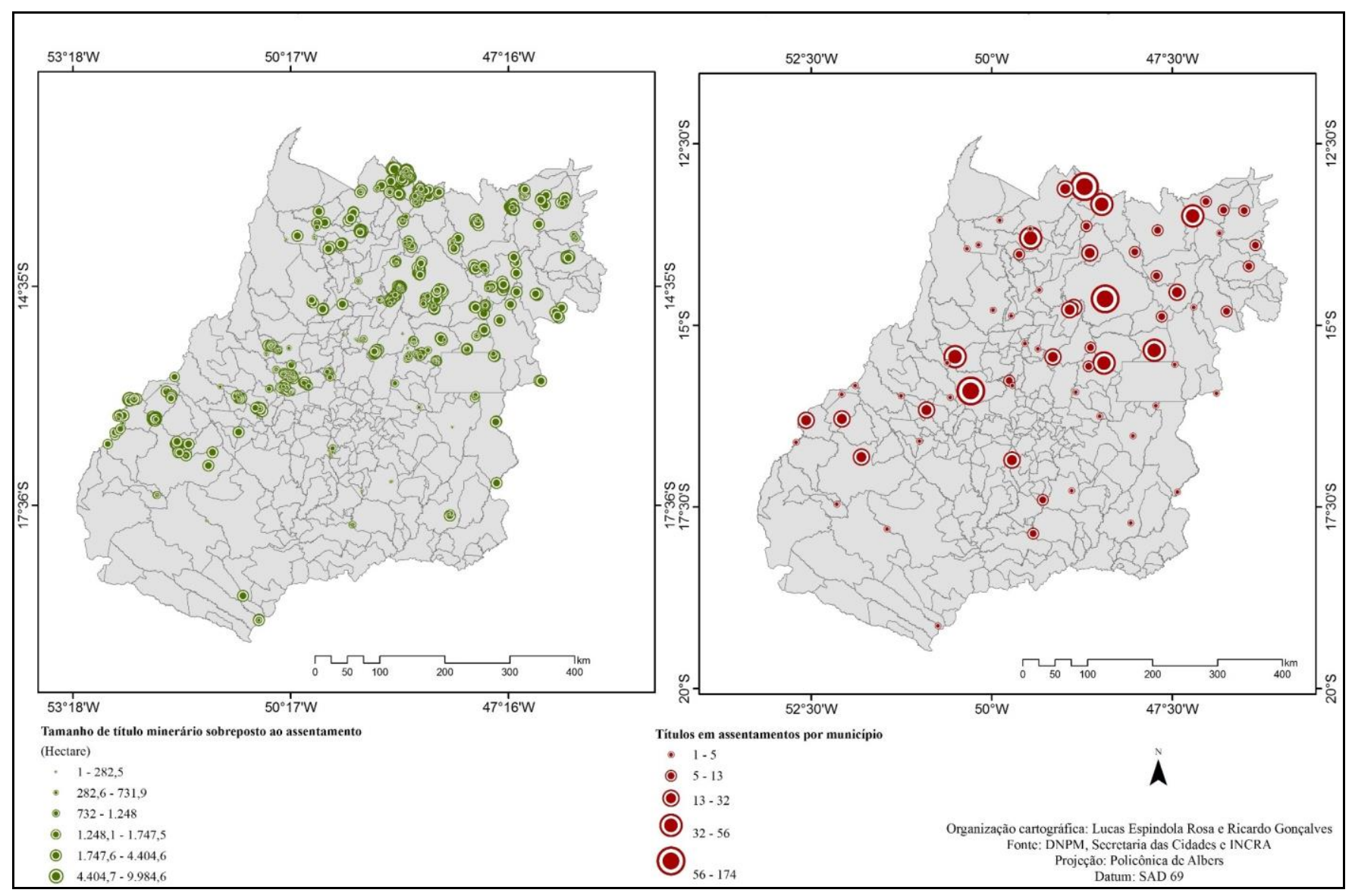

Mapa 5 - Sobreposição entre áreas de assentamentos rurais e interesses minerários (tamanho [em hectares] e quantidade de títulos em assentamentos por município) em Goiás.

Concepção: o autor (2016).

Elaboração: Espíndola Rosa, L., (2016).

Os assentamentos rurais também são resultados de uma política em prol do interesse nacional. Uma política baseada no exercício da função social da terra, da sustentabilidade socioambiental, soberania alimentar e condições de vida e trabalho dignas no campo. No entanto, até mesmo neste exemplo, cabe às autoridades administrativas federais, representadas pela ANM e INCRA, a faculdade de decidir a atividade que melhor contribui para o desenvolvimento nacional na atualidade - a mineração ou o assentamento onde estão localizadas as jazidas minerais. (ANM, 2014).

[...] a rigidez locacional das jazidas minerais, bem como a existência de direitos minerários que compreendem a área inserida na região que pretende-se a realização de assentamento, os interesses envolvidos na realização de reforma agrária deverão ser cabalmente contrastados àqueles decorrentes da atividade minerária pelas autoridades administrativas de ambas as autarquias federais envolvidas - DNPM e INCRA - em exercício de atividade discricionária informada pelos critérios da oportunidade e conveniência, de forma a se evidenciar, in casu, qual das duas atividades irá melhor contribuir para o desenvolvimento nacional na atualidade. (DNPM, 2014, apud MALERBA, 2015, p.1). 
O maior número de títulos em áreas de assentamentos rurais estão localizados nos municípios de Niquelândia, Teresina de Goiás, Amaralina, Montividiu do Norte, Niquelândia, Barro Alto e Faina. (Tabela 3).

\begin{tabular}{c|c|c|c} 
Assentamento & Município & $\mathbf{N}^{\circ}$ de títulos & Minérios de interesse \\
\hline Rio Vermelho & Niquelândia & 106 & $\begin{array}{c}\text { Areia, Calcário, Manganês, } \\
\text { Ouro }\end{array}$ \\
\hline $\begin{array}{c}\text { Floriano Cardoso } \\
\text { dos Santos }\end{array}$ & $\begin{array}{c}\text { Montividiu do } \\
\text { Norte }\end{array}$ & 57 & $\begin{array}{c}\text { Cromo, Ferro, Estanho, Granito, } \\
\text { Ouro, Terras Raras, Titânio }\end{array}$ \\
\hline Diadema & $\begin{array}{c}\text { Teresina de } \\
\text { Goiás }\end{array}$ & 55 & $\begin{array}{c}\text { Areia, Estanho, Ferro, Ouro, } \\
\text { Tântalo }\end{array}$ \\
\hline Acaba Vida & Niquelândia & 42 & Ouro, Níquel, Talco \\
\hline Ferrão I & Amaralina & 36 & $\begin{array}{c}\text { Ouro, Fosfato, Níquel, Quartzo, } \\
\text { Quartizito }\end{array}$ \\
\hline Santa Fé da Laguna & Barro Alto & 32 & Ilmenita, Níquel, Titânio \\
\hline $\begin{array}{c}\text { São José do } \\
\text { Piçarrara }\end{array}$ & Faina & 22 & Calcário, Ouro
\end{tabular}

Tabela 3 - Apropriação e controle do subsolo em área de assentamentos rurais em Goiás - 2015. Fonte: INCRA (2015); DNPM (2015); ESPÍNDOLA ROSA (2015).

Org.: o autor (2015).

Observa-se o interesse por minérios como ouro e níquel, em municípios como Faina, Barro Alto e Niquelância, onde grandes projetos da indústria mineral extrativa já estão territorializados ou em andamento para a lavra desses recursos. Enfatizando a concentração de títulos minerários, em Niquelândia, além dos Assentamentos Rio Vermelho e Acaba Vida, há outros quatro Assentamentos com sobreposição de títulos minerários, sendo Aranha, Conceição, Engenho do Bom Jesus e Santa Rita do Boreiro. Em Montividiu do Norte, além do Assentamento Floriano Cardoso dos Santos, outros sete Assentamentos (Ana Terra, Boa Vista do Norte,Curral da Pedra, João Rufino da Silva, Pedra Azul, Santa Fé e Santa Júlia), possuem áreas de subsolo apropriadas por interesses minerários. Por sua vez, quanto ao número de assentamentos com títulos em áreas dos lotes, a Cidade de Goiás se destaca. São dezesseis assentamentos com títulos minerários interessados em minérios como ouro, cobre, níquel e titâneo (INCRA, 2015; DNPM, 2015; ESPÍNDOLA ROSA et.al, 2015).

As contradições representadas pela estratégia de controle do subsolo nos assentamentos rurais em Goiás ficam mais evidentes quando percebe-se que apenas seis empresas são "donas" de 21\% dos títulos, ou seja, 210 do total de 1093 eventos verificados no estado. São elas: Mineração Maracá Indústria e Comércio S.A; Serra Verde Pesquisa e Mineração Ltda; Anglo American Níquel Brasil Ltda; Empresas Votorantim S.A; Mineração 
Goiás Velho Ltda. Dessa forma, concentrados nas mãos de capitalistas privados nacionais e estrangeiros. Enquanto isso, famílias camponesas lutam para permanecer na terra e no território dos assentamentos, muitas vezes sem condições básicas para a produção social da existência, como saúde, educação, água encanada e energia elétrica. Desse modo, acredita-se que essa realidade também sublinha potenciais conflitos, que podem agravar a questão agrária em Goiás.

No Brasil, exemplos de conflitos entre a territorialização dos grandes projetos de extrativismo mineral e áreas de assentamentos já são mapeados e discutidos a partir das estratégias de resistências de lideranças locais e de movimentos sociais como o Movimento dos Trabalhadores Sem Terra (MST) e o Movimento pela Soberania Popular na Mineração (MAM). Em novembro de 2013, Charles Trocate (2013, p.1) em entrevista publicada pelo Brasil de Fato, afirmou que "em nível nacional, dos 24 estados em que há a organização do MST, 14 deles existem assentamentos impactados pela mineração”. Com efeito, diferentes formas de lutas estão sendo construídas, tanto diante dos impactos da mineração ou restrição a implementação de novos projetos pela indústria extrativa mineral. Um exemplo disso é o Assentamento Reseli Nunes, no município de D’Oeste, Mato Grosso, e que abriga 330 famílias assentadas, em cujo subsolo foram descobertos depósitos de minério de ferro e fosfato (MALERBA, 2015).

Finalmente, compreende-se que a análise do espaço agrário em Goiás, especialmente no campo da Geografia Agrária, é imprescindível do papel que a mineração em grande escala exerce na economia, no ambiente e nas estratégias de apropriação dos recursos territoriais.

\section{CONSIDERAÇÕES FINAIS}

Os resultados apresentados na pesquisa contribuem com as interpretações geográficas do espaço agrário e chamam a atenção para o papel que a mineração exerce nas formas de controle e usos dos bens comuns naturais. Destaca-se que a mineração envolve uma rede de produção complexa, que integra processos de pesquisa geológica, explotação mineral, transformação industrial, descarte de rejeitos, transporte e consumo em diferentes escalas, regionais, nacionais e internacionais. Portanto, resulta em redes de efeitos e conflitos socioambientais que não se reduzem ao entorno da mina. Estruturas como ferrovias, minerodutos, plataformas portuárias, pilhas de estéril e barragens de disposição de rejeitos 
operam de maneira integra na mineração e implicam na fratura do espaço agrário por meio de conflitos, desastres e despojo de populações tradicionais.

No decorrer da primeira década do século XXI o Brasil intensificou sua economia agroexportadora e a mineração foi fundamental para manter o país integrado às redes globais de commodities. No período de boom das commodities minerais (2003-2011), a exploração, os ritmos extrativos e as exportações de minérios foram intensificadas. De maneira contraditória, internamente, acentou-se a fratura territorial de comunidades e da saúde dos trabalhadores. Sendo assim, Goiás participou desse processo e continua sendo um entre os três principais estados minerados do país, conectado às redes globais extrativas como importante produtor e exportador de minérios como ouro, níquel e nióbio. Por isso, as implicações da mineração em grande escala revelam um espaço agrário fraturado.

Além disso, a agudização dos interesses das corporações por minérios expandiu as fronteiras extrativas e as ações para controlar jazidas do subsolo com potencial de exploração, lavra ou apenas artifício especulativo em tempos de boom das commodities. Em Goiás, os requerimentos e títulos minerários em áreas ocupadas por comunidades quilombolas, camponeses posseiros e assentamentos rurais representam ameaças de conflitos latentes em territórios ocupados por sujeitos que vivem do uso tradicional da terra. Essa situação pode ser agravada diante das decisões de um governo de extrema direita. Contribuem com esta constatação as afirmações do atual (março de 2019) ministro de minas e energia na maior feira anual de mineração do mundo - o Prospectors and Developers Association of Canada (PDAC), em Toronto, no Canadá -, de que o governo planeja avaliar a viabilidade de ampliar o acesso aos minérios em áreas restritivas à mineração, como as terras indígenas e faixas de fronteira (VALOR ECONÔMICO, 2019).

Em síntese, observa-se que o modelo de mineração no Brasil opera de maneira depredadora e conectado ao que Wisnik (2018, p.228) chama de "economia do saque ambiental". É um modelo de extrativismo que não combina com sustentabilidade ao exaurir os bens comuns naturais, impor processos de desterritorialização compulsivos, fomentar desigualdades sociais, econômicas e políticas, precarização e adoecimento de trabalhadores. É um modelo que exige mudanças radicais, com controle das escalas e ritmos extrativos, usos de água, energia e minérios; combate às práticas de evasão de divisas e sonegação fiscal; políticas minerárias, ambientais e trabalhistas discutidas com participação popular; autonomia das populações e comunidades para decidir o destino e os usos dos seus territórios; definição 
de áreas livres de mineração ou construção de infraestruturas conexas, como as barragens de rejeitos. Por fim, isso é necessário sem que grandes desastres sociotécnicos como em Mariana/MG e Brumadinho/MG voltem a acontecer.

\section{REFERÊNCIAS BIBLIOGRÁFICAS}

ALMEIDA, C. A terra é deles. A luta é provar. 2014. Disponível em: <https://www.opopular.com.br>. Acesso em: 28 de jun., 2015.

ANM - Agência Nacional de Mineração. Arrecadação CFEM. 2017. Disponível em: < https://sistemas.dnpm.gov.br/arrecadacao/extra/Relatorios/arrecadacao_cfem.aspx >. Acesso em: 20 Fev 2019.

. Desempenho do setor mineral: Goiás e Distrito Federal. DNPM - 6º DS/GO, 2005.

Desempenho do setor mineral: Goiás e Distrito Federal. DNPM - 6 DS/GO, 2014.

BANCO MUNDIAL. Global Economic Monitor (GEM) Commodities. 2016. Disponível em: <http://databank.worldbank.org>. Acesso em: 20 de jun., 2016.

BRASIL, Constituição (1988). Constituição da República Federativa do Brasil. Brasília, DF: Senado Federal, 1988.

CPRM. Mapa geológico de Goiás. 2000. Disponível em: cprm.gov.br. Acesso em: 03 de mar., 2019.

ESPÍNDOLA ROSA, L. et.al. Análise das áreas de conflito entre assentamentos rurais e mineração no Estado de Goiás. ANAIS. Simpósio Internacional de Geografia Agrária SINGA, Goiânia/Goiás, 2015. p. 1931-1942.

GALEANO, E. As veias abertas da América Latina. Tradução de Galeano de Freitas. Rio de Janeiro: Paz e Terra, 1987.

GONÇALVES, R. J. A. F. No horizonte, a exaustão: disputas pelo subsolo e efeitos socioespaciais dos grandes projetos de mineração em Goiás. 504f. Tese (Doutorado em Geografia) - Universidade Federal de Goiás, Programa de Pós-graduação em Geografia, 2016. . et.al. Neoextrativismo liberal-conservador: a Política Mineral e a Questão Agrária no Governo Temer. OKARA: Geografia em debate, v.12, n.2, p. 348-395, 2018

HARVEY, D. A loucura da razão capitalista: Marx e o capital no século XXI. Tradução de Artur Renzo. São Paulo: Boitempo, 2018.

IMB. Goiás em dados 2017. Goiás: Goiânia, 2018.

INCRA GOIÁS. Os assentamentos em Goiás. 2015. Disponível em: <https://incragoias.wordpress.com/distribuicao-dos-assentamentos-no-estado-de-goias/>. Acesso em: 20/06/2016.

ITC. Trade map. 2017. Disponível em http://www.trademap.org/Index.aspx>. Acesso em: 23 de mar., 2017. 
MALERBA, J. Mineração e questão agrária: as reconfigurações da luta pela terra quando a disputa pelo solo se dá a partir do subsolo. In: CPT (Ed.). Conflitos no Campo - Brasil 2015. Goiânia: CPT Nacional, 2015. p.78-85.

MILANEZ, B. Boom ou bolha? A influência do mercado financeiro sobre o preço do minério de ferro no período 2000-2016. Versos -Textos para Discussão PoEMAS, 1(S2), 1-18, 2017.

PERPETUA, G. M. Pilhagem territorial, precarização do trabalho e degradação do sujeito que trabalha: a territorialização do capital arbóreo-celulósico no Brasil contemporâneo. 307f. Tese (Doutorado em Geografia) - Programa de Pós-graduação em Geografia, UNESP, Presidente Prudente, 2016.

SANTOS, R. S. P. O projeto neoextrativista e a disputa por bens naturais no território: mineração, direitos e contestação social em torno da terra e da água. In: CPT (Ed.). Conflitos no Campo - Brasil 2012. Goiânia: CPT Nacional, 2012. p.75-86.

STF. STF reafirmar inconstitucionalidade de dispositivo que permitia extração de amianto crisotila. 2017. Disponível em: <http://www.stf.jus.br/>. Acesso em: 04 de mar., 2019.

TROCATE, C. A luta dos atingidos pela mineração. 2013. Disponível em: <https://www.brasildefato.com.br/node/26487/>. Acesso em: 28 de jan., 2019.

WANDERLEY, L. J. Do boom ao pós-boom das commodities: o comportamento do setor mineral no Brasil. Versos - Textos para Discussão PoEMAS, v. 1, n. 1, p. 1-7, 2017.

WISNIK, J. M. Maquinação do mundo: Drummond e a mineração. São Paulo: Companhia das Letras, 2018.

VALOR ECONÔMICO. Ministro diz que governo planeja liberar mineração em terras indígenas. 2019. Disponível em: <https://www.valor.com.br. Acesso em: 05 de marc., 2019. 